\title{
Mesoporous Iron Adsorbent: A Novel Technique for Arsenic Removal from Contaminated Water
}

\author{
Dr. Chanchal Majumder \\ Assistant professor, Civil Engineering Department, Bengal Engineering and Science University \\ West Bengal, India \\ Email: chanchal@ civil.becs.ac.in
}

\begin{abstract}
In this work mesoporous silica (MS) material was synthesized using block-co-polymer and used as an adsorbent support for arsenic removal. To meet this requirement, mesoporous silica (MS) with a large surface area $\left(262.13 \mathrm{~m}^{2} / \mathrm{g}\right)$ and uniform pore size (about $42 \AA$ ) was prepared. This study showed that MS with a wide surface area, uniform pore size, and interlinked pore system can be synthesized at very low block-co-polymer concentration $(1.0 \mathrm{mM})$ and can be used as an efficient adsorbent support for the removal of arsenic. The post synthesis modification of MS support was done by doping with different amount of iron precursor to study the arsenic removal efficiency. The results show that the MS impregnated with $20 \%$ by weight of iron precursor have higher arsenic removal efficiency and better arsenic removal kinetics. The maximum removal was observed at slight acidic $\mathrm{pH}$ value of 6.0.
\end{abstract}

Keywords-Mesoporous silica; block-co-polymer; adsorbent; precursor; Arsenic

\section{INTRODUCTION}

Arsenic is creating potentially serious environmental problems for humans and other living organisms by contaminating the groundwater. The most reported arsenic problems are found in groundwater supply systems and are caused by natural processes such as mineral weathering and dissolution caused by the changes of geochemical environments to reductive conditions [1]. Arsenic contamination is also caused by human activities such as mining wastes, petroleum refining, sewage sludge, agricultural chemicals, ceramic manufacturing industries, and coal fly ash [2,3]. The chronic toxicity of arsenic in drinking water is known to cause various types of cancer and black foot disease The U.S. EPA has classified arsenic as a carcinogen and drinking water arsenic standard of 0.01 $\mathrm{mg} / \mathrm{l}$.

An ideal adsorbent should have uniformly accessible pores, a high surface area, and physical and/or chemical stability [4]. The adsorption rate of activated alumina (AA) is slow as compared to the surface adsorption onto a metal hydroxide. This slow kinetics can be attributed to the diffusion of arsenic species into the irregular pore structure, and the longer transport path involved for the coarse AA [5]. Such conventional porous solids with an ill-defined pore structure and bottleneck normally show low adsorption capacities and slow kinetics of adsorption. Porous materials with a controlled mesostructure are of fundamental importance in science and engineering and have continued to attract great interest in a variety of applications, including organic or metal ion adsorbents, catalyst support etc. [6, 7]

SBA-15 molecular sieve has a higher hydrothermal

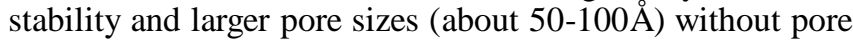
expanding chemicals; therefore, it can likely incorporate a large portion of the metal precursor without blocking effects [8]. In addition, water or ethanol extraction can be applied to recover the pore-forming template for reuse in SBA-15 synthesis due to the weak interaction between twodimensional hexagonal silica and triblock copolymer mesophases [9]. SBA-15 silica materials cab be synthesized with high surface area of $600-1000 \mathrm{~m}^{2} / \mathrm{g}$ and a pore volume of $0.6-1.3 \mathrm{~cm}^{3} / \mathrm{g}$, which provide highly active sites for applications to adsorption, catalysis, or sensors [10].

The objectives of this study were as follows:

I. to synthesizing highly ordered mesoporous silica SBA-15 and incorporating iron oxides onto the SBA-15 surface by use of an incipient-wetness impregnation technique and to evaluate the adsorption of arsenate species on it.

II. to evaluate the effect of $\mathrm{pH}$, adsorbent dose etc. on arsenic removal.

\section{EXPERIMENTAL}

\section{A. Determination of Critical Miceller Concentration (CMC).}

The basic principle of synthesizing the mesoporous material is that at critical miceller concentration the surfactant materials form micelles. As no such data regarding $\mathrm{CMC}$ value of $\mathrm{P} 123$ Block-co-polymer is reported, attempt is made to find the CMC value of the polymer used. This is done in a view to avoid excess loss of costly polymer during calcinations. This is being done depending on the physical phenomena that at critical miceller concentration turbidity, conductivity, osmotic pressure or surface tension changes abruptly. We measured the conductivity parameter and obtained the $\mathrm{CMC}$ value at about $1.0 \mathrm{mM}$ concentration for Pluronic P123, $\left(\mathrm{EO}_{20}-\mathrm{PO}_{70} \mathrm{EO}_{20}, \mathrm{MW}=5800\right)$ block co polymer.

\section{B. Materials and Methods}

The synthesis of mesoporous material was carried out slightly above the CMC of the triblock copolymer. SBA-15 mesoporous silica was synthesized using a triblock copolymer (Pluronic P123, $\mathrm{EO}_{20}-\mathrm{PO}_{70} \mathrm{EO}_{20}$, Aldrich) as a template and tetraethyl orthosilicate (TEOS, Merck) as a silica precursor. The synthesis was carried out by standard procedure as described elsewhere [11]. In a typical batch 
synthesis, $12 \mathrm{gm}$ of polymer was dissolved in 2 litres of deionized water and $100 \mathrm{ml}$ of $\mathrm{HCl}(35 \%)$ is added and mixed thoroughly by stirring with magnetic stirrer for about $12 \mathrm{hr}$. In this solution $55 \mathrm{ml}$ of TEOS is added and stirred for another three hours. On addition of TEOS a whitish sol-gel is formed. It is then heated at $35^{\circ} \mathrm{C}$ for three days without stirring. The white solid product was precipitated and then filtered from the mixture with a $0.45-\mu \mathrm{m}$ filter, washed with deionized water and dried at room temperature under vacuum before calcination. The mole fraction of each component for as-synthesized SBA-15 was 1 mol TEOS: $13.168 \mathrm{~mol} \mathrm{HCl}: 452.5906 \mathrm{~mol} \mathrm{H}_{2} \mathrm{O}$ : 0.00843 mol triblock copolymer. Calcination was performed in an oven at $550{ }^{\circ} \mathrm{C}$ for $6 \mathrm{~h}$ to remove the triblock copolymer organic component. The calcined SBA-15 was preserved at room temperature under vacuum. $\mathrm{Fe}\left(\mathrm{NO}_{3}\right)_{3}, 9 \mathrm{H}_{2} \mathrm{O}$ was selected as iron, precursors, to incorporate metals into SBA-15 through use of an incipient wetness impregnation technique. The $10 \%$ of aluminum impregnated SBA-15 (weight of aluminum/ weight of SBA-15) was designated as $\mathrm{Al}_{10} \mathrm{SBA}-15$ and so on.. All solids were then calcined again in an oven at $550^{\circ} \mathrm{C}$ and the temperature is then hold for $4 \mathrm{hr}$. After calcination, the material so developed is cooled down at room temperature and the solids were kept inside a vacuum chamber for adsorption study.

\section{Characterization of Synthesized Materials}

X-ray diffraction (XRD) patterns were obtained using a Stoe High-Resolution X-ray Diffractometer (Philips Analytical X-Ray B.V.) equipped with Mo radiation $(40 \mathrm{kV}$, $25 \mathrm{~mA}$ ) with a $0.05^{\circ}$ step size and $1 \mathrm{~s}$ step time over the range $5^{\circ}<2 \theta<25^{\circ}$. The morphology was studied by scanning electron microscopy. $\mathrm{N}_{2}$ gas adsorption isotherms were performed at $77.35^{\circ} \mathrm{K}$ using a autosorb As-1-MP analyzer (Quantachrome, USA). The out gassing temperature was $200^{\circ} \mathrm{C}$.The BET specific surface area was calculated using the linear portion of the BET equation. The pore size distributions of media were obtained using Barrett, Joyner, and Halenda $(\mathrm{BJH})$ analysis [12] of the desorption branch of the hysteresis loop of the nitrogen adsorption isotherm. The pore diameter $\left(\mathrm{D}_{\mathrm{BJH}}\right)$, mesopore surface area $\left(\mathrm{A}_{\mathrm{BJH}}\right)$, and volume $\left(\mathrm{V}_{\mathrm{BJH}}\right)$ were calculated from the pore size distribution curve.

\section{Arsenate Adsorption Isotherm and Kinetic Tests.}

Sodium arsenate $\left(\mathrm{Na}_{2} \mathrm{HAsO}_{4}, 7 \mathrm{H}_{2} \mathrm{O}\right.$, LOBA) was used as the arsenate source without any modification. Arsenate stock solution was prepared at a concentration of $1.0 \mathrm{mg} / \mathrm{l}$ in deionized water. From this stock solution intermediate strength of $0.20 \mathrm{mg} / \mathrm{l}$ arsenate prepared with deionized water and used as sample. The samples were set in a wrist shaker at room temperature $\left(25^{\circ} \mathrm{C}\right)$. After $8 \mathrm{~h}$ of shaking, the $\mathrm{pH}$ of the samples was readjusted with $0.1 \mathrm{M} \mathrm{NaOH} / \mathrm{HCl}$ ). All samples were then shaken again until equilibrium was reached. After $12 \mathrm{~h}$ of shaking, the samples were withdrawn and filtered with a $0.45-\mu \mathrm{m}$ filter paper. For kinetic study six samples of $50 \mathrm{ml}$ each with arsenate concentration of $0.2 \mathrm{mg} / \mathrm{l}$ was taken in Erlenmeyer flax and set to a wrist shaker. The samples were collected at some intervals, filtered with $0.45 \mu \mathrm{m}$ whattman filter paper and the percent removals were calculated. Arsenate was analyzed with the help of an Atomic Absorption Spectrophotometer with attachment of continuous Hydride Vapour Generation (AA202, Chemito, India).

\section{RESUltS AND DISCUSSION}

\section{A. Characterization of $M A$.}

Experimental result of critical micelle determination revealed approximately $1 \mathrm{mM} / 1$. MA prepared using a chemical template (triblock co-polymer) showed a narrow pore size distribution with a pore diameter of about $42 \AA$, a high surface area $\left(262.13 \mathrm{~m}^{2} / \mathrm{g}\right)$, and a high pore volume (ca $0.3100 \mathrm{cc} / \mathrm{g}$ ). The location of the hysteresis loop in the $\mathrm{N}_{2}$ adsorption isotherm can be used to determine whether the material possessed a regular framework pore or interparticle voids, such as a textural pore. The framework porosity at $0.42-0.73 \mathrm{P} / \mathrm{Po}$ in the $\mathrm{N}_{2}$ isotherm for mesoporous silica indicates that the porosity was contained within the uniform channels of the templated framework, while the textural porosity at $0.8-1 \mathrm{P} / \mathrm{Po}$ shows porosity arising from the noncrystalline intra-aggregate voids and spaces formed by interparticle contacts [13]. As shown in Fig.1, MA shows the presence of only framework porosity. This suggests that this MA has a regular pore structure.

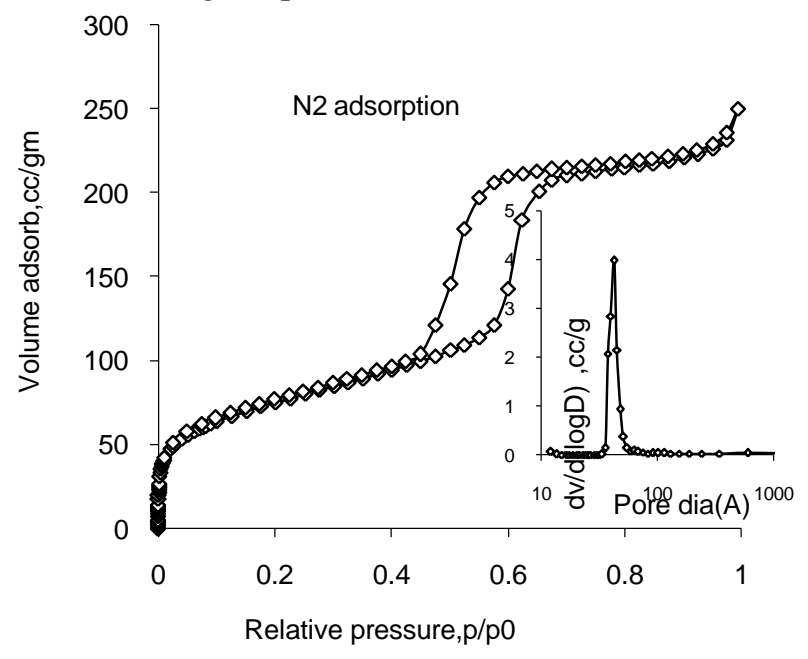

Figure 1. N2 adsorption/ desorption of MS

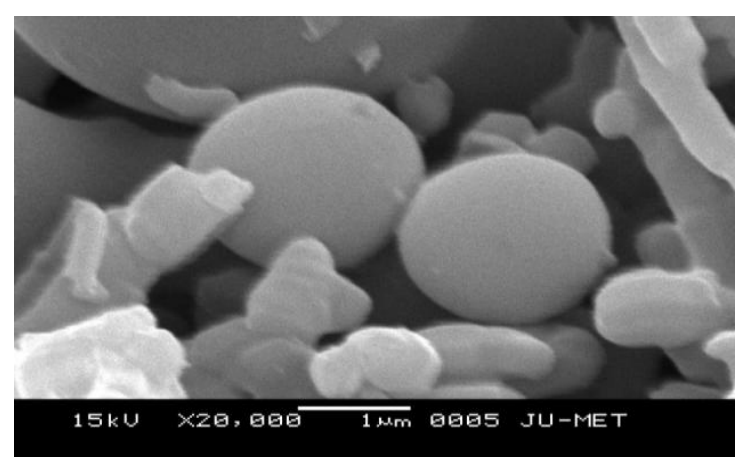

Figure 2. SEM image of pristine SBA15 
The X-Ray analysis (not in picture) of mesopore silica show crystalline structure, but when iron precursor is incorporated and calcined, the material changes to amorphous nature, may be due to collapse of crystalline structure of pristine mesoporous silica. The scanning electron microscopy (Figure 2) revels that the particles formed are in range of one to two micron size.

\section{B. Effect of $p H$.}

The uptake of arsenate by MA in different $\mathrm{pH}$ is shown in Fig. 3. It is clear that the adsorption by mesoporous iron is dependent on the solution $\mathrm{pH}$ and that the maximum uptake is obtained at $\mathrm{pH}$ 6. The arsenate ion occurs mainly in the form of $\mathrm{H}_{2} \mathrm{AsO}_{4}{ }^{-}$in the $\mathrm{pH}$ range between 3 and 6 , while a divalent anion $\mathrm{HAsO} 4^{2-}$ dominates at higher $\mathrm{pH}$ values (such as between $\mathrm{pH} 8$ and $\mathrm{pH}$ 10.5). In the intermediate region (i.e., in the $\mathrm{pH}$ range between 6 and 8), both species coexist with one another [3]. Thus, it is evident that the main species, $\mathrm{H}_{2} \mathrm{AsO}_{4}{ }^{-}$adsorbed by mesoporous iron at a $\mathrm{pH}$ of 6.0 Adsorption does not occur at high $\mathrm{pH}$ levels, and thus a high $\mathrm{pH}$ range can be used for a desorption test.

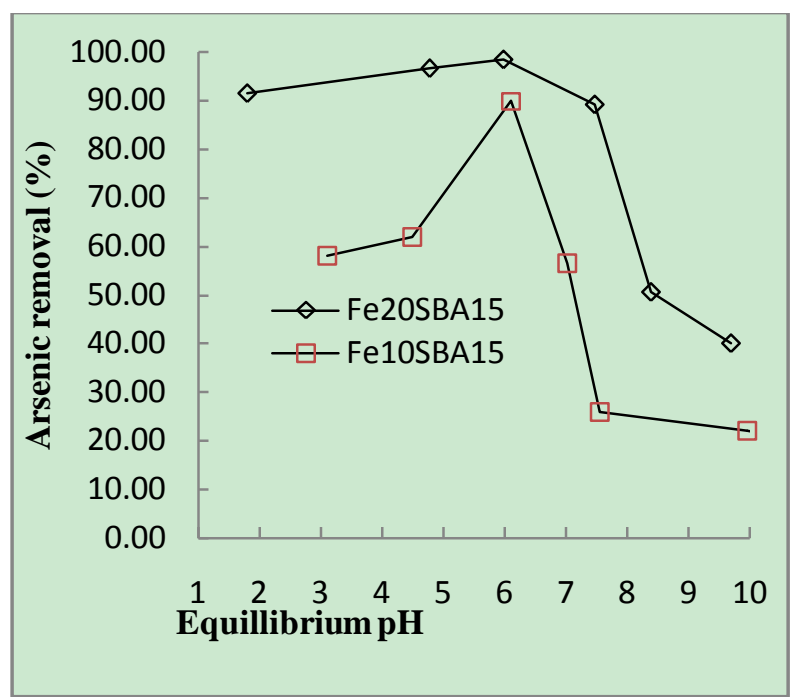

Figure 3. Effect of $\mathrm{pH}$ on arsenic removal

\section{Adsorption Equilibrium Study}

Langmuir and Freundlich isotherms were examined in the present study. A basic assumption in the Langmuir theory is that sorption takes place at specific homogeneous sites within the adsorbent The Langmuir isotherm is expressed as follows

$$
\mathrm{X} / \mathrm{m}=\left(\mathrm{K}_{1} \mathrm{~K}_{2} \mathrm{C}_{\mathrm{eq}}\right) /\left(1+\mathrm{K}_{1} \mathrm{C}_{\mathrm{eq}}\right)
$$

where, $\mathrm{k}_{2}(\mathrm{mg} / \mathrm{g})$ is the maximum adsorption capacity corresponding to complete monolayer coverage, $\mathrm{C}_{\mathrm{eq}}(\mathrm{mg} / \mathrm{l})$ is the equilibrium solute concentration, and ' $\mathrm{k}_{1}$ ' is the equilibrium constant related to the energy of sorption $(1 / \mathrm{g})$, which also may be termed as distribution co-efficient of solute in solid phase and liquid phase. X (mg) is the sorbed amount of adsobate and ' $m$ ' is adsorbent dose $(\mathrm{g})$. The Langmuir isotherms for both $\mathrm{Fe}_{10} \mathrm{SBA} 15$ and $\mathrm{Fe}_{20} \mathrm{SBA} 15$ are plotted in Fig. 4. It is evident from Figure 4 that $\mathrm{Fe}_{20} \mathrm{SBA} 15$ fits the Langmuir adsorption model better than $\mathrm{Fe}_{10} \mathrm{SBA} 15$.

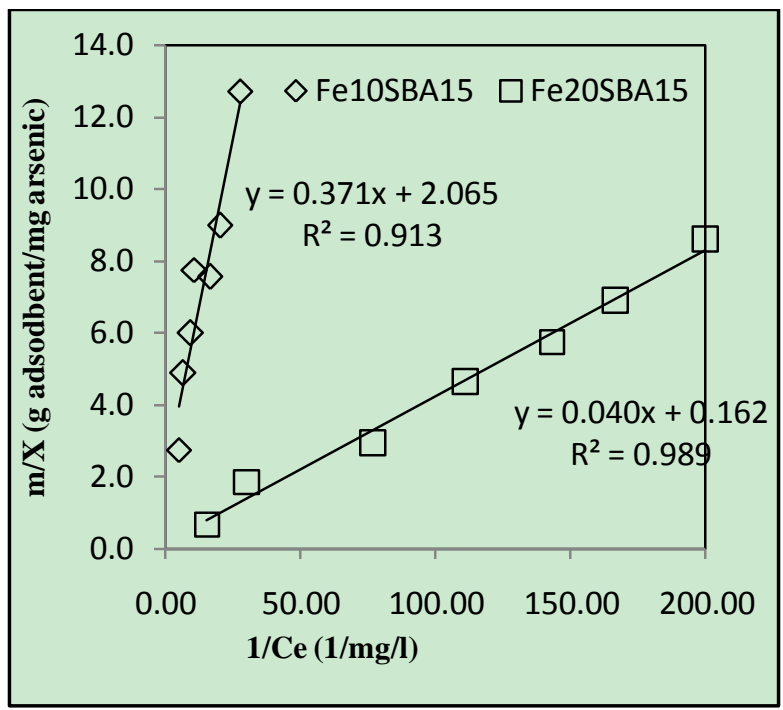

Figure 4. Adsorption isotherm

The Freundlich isotherm model was also tested to describe the adsorption data. It assumes that different sites are involved with several adsorption energies [14].The Freundlich isotherm is expressed as follows:

$$
\mathrm{X} / \mathrm{M}=\mathrm{K} \mathrm{C}^{1 / \mathrm{n}}
$$

Where, $\mathrm{C}=$ equilibrium concentration, $k, n$ are empirical constants. It is evident from the Fig.5 that $\mathrm{Fe}_{20} \mathrm{SBA} 15$ fits Freundlich isotherm better than $\mathrm{Fe}_{10} \mathrm{SBA} 15$. The correlation Corelation coefficient $\left(\mathrm{R}^{2}\right)$ of the isotherms shows that Freundlich and Langmuir isotherms fit good for both the materials.

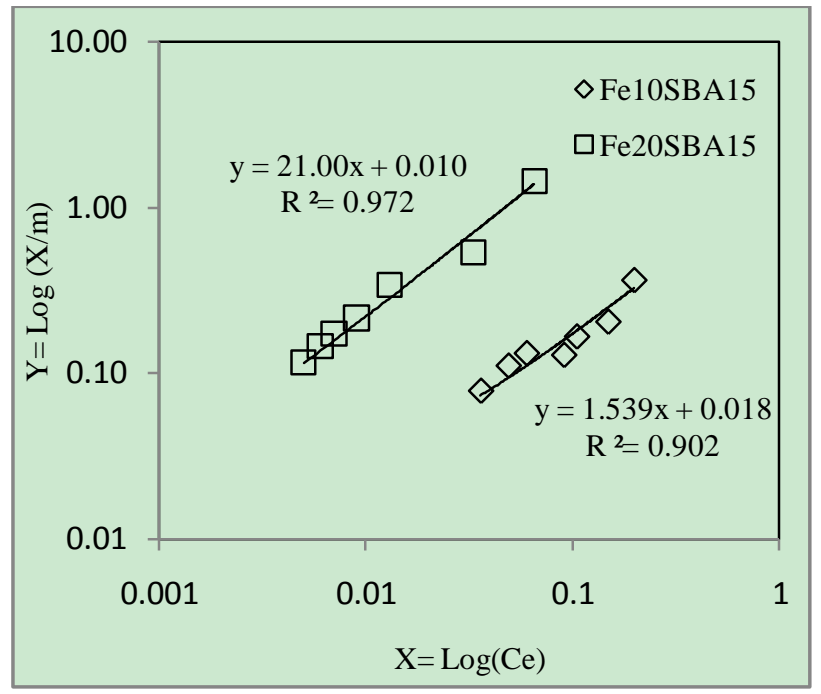

Figure 5. Freundlich isother 


\section{CONCLUSIONS}

This study reveals that mesoporous silica with uniform pore size can be synthesized with block-co-polymer concentration as low as $1 \mathrm{mM} / 1$. The uniform pore size in mesoporous silica helps in faster intake of arsenic. In this study a uniform pore size of about $42 \AA$ \& was synthesized. The experiments revels that $20 \%$ (wt.) iron impregnated mesoporous silica have very good arsenic removal kinetic and isotherm.

The material show good fits with Langmuir isotherm than Freundlich isotherm. The optimum $\mathrm{pH}$ range for arsenate removal was found to be 5.0-6.0. At this $\mathrm{pH}$ range the mesoporous iron surface is found to be positively charged. The kinetic study reveals that pseudo-second order rate equation fits excellent $\left(\mathrm{R}^{2}=1\right)$.

\section{ACKNOWLEDGMENTS}

This work was supported by University Grants Commission, Govt. of India vide order no: F No.31-37/ 2005 (SR) under Minor Research Scheme. The author sincerely acknowledge the contributions from Dr. Amitava Basu Mallick, Metallergical Engineering Division, Bengal Engineering and Science University, Shibpur, India for XRD analysis and Dr. Somen Roy (Membrane Laboratory) of Central Glass and Ceramic Research Institute, Kolkata, India, for surface area and pore size analysis.

\section{REFERENCES}

[1] X. C. Le, S. Yalcin, and M. Ma, " Speciation of Submicrogram per Liter Levels of Arsenic in Water: On-Site Species Separation Integrated with Sample Collection," Environ. Sci. Technol. , pp 2342-2347,2000

[2] T. Viraraghavan, K. S. Subramanian and J. A. Aruldoss, "Arsenic in drinking water-problems and solutions," Water Science and Technology, Vol. 40., No. 2, pp 69-76, 1999

[3] B. A. Manning and S. Goldberg, "Adsorption and Stability of Arsenic(III) at the Clay Mineral-Water Interface," Environ. Sci.
Technol., 31 (7), pp 2005-2011, 1997

[4] H. Yoshitake, T. Yokoi,and T. Tatsumi, "Adsorption of Chromate and Arsenate by Amino-Functionalized MCM-41 and SBA-1," Chem. Mater., Vol.14, No.11, pp 4603-4610, 2002

[5] T.F. Lin, J.K. Wu, "Adsorption of Arsenite and Arsenate within Activated Alumina Grains: Equilibrium and Kinetics," Water Res.,Vol. 35, No. 8, , Pages 2049-2057, 2001

[6] V. Q. Chiu and J. G. Hering, "Arsenic Adsorption and Oxidation at Manganite Surfaces. 1. Method for Simultaneous Determination of Adsorbed and Dissolved Arsenic Species," Environ. Sci. Technol, vol.34, No.10, pp 2029-2034, 2000

[7] A. I. Zouboulis and I. A. Katsoyiannis, "Arsenic Removal Using Iron Oxide Loaded Alginate Beads," Ind. Eng. Chem. Res., vol.41, No.24, pp 6149-6155, 2002

[8] D. Zhao, J. Feng, Q. Huo, N. Melosh, G. H. Fredrickson, B. F Chmelka, G. D. Stucky, " Triblock copolymer syntheses of mesoporous silica with periodic 50 to 300 angstrom pores," Science, vol.279, No.5350, pp548-552, 1998

[9] M. Kruk , M. Jaroniec , C. H. Ko and R. Ryoo, "Characterization of the Porous Structure of SBA-15, Chem. Mater., Vol.12, No.7, pp 1961-1968, 2000

[10] M. S. Morey, S. O.Brien, S. Schwarz, and G. D. Stucky, "Hydrothermal and postsynthesis surface modification of cubic, MCM-48, and ultralarge pore SBA-15 Mesoporous Silica with titanium," Chemistry of Materials, Vol.12, No. 4, pp 898-911,2000

[11] M. Jang, E. W. Shin, J. K. Park, and S. I. Choi, "Mechanisms of Arsenate Adsorption by Highly-Ordered Nano-Structured Silicate Media Impregnated with Metal Oxides," Environ. Sci. Technol.,Vol.37, No.21, pp 5062-5070,2003

[12] E. P. Barrett, L. G. Joyner , P. P. Halenda, "The Determination of Pore Volume and Area Distributions in Porous Substances. I. Computations from Nitrogen Isotherms," J. Am. Chem. Soc.,Vol., 73, No. 1, pp 373-380, 1951

[13] P. T. Tanev and T. J. Pinnavaia, "Mesoporous Silica Molecular Sieves Prepared by Ionic and Neutral Surfactant Templating: A Comparison of Physical Properties," Chemistry of Materials, , vol.8, No.8, pp 2068-2079, 1996

[14] Z. Reddad, C. Gerente, Y. Andres, and P.L. Cloirec, "Adsorption of Several Metal Ions onto a Low-Cost Biosorbent: Kinetic and Equilibrium Studies," Environ. Sci. Technol., vol.36 No.9, pp 20672073, 2002 